\title{
La diligencia como elemento del derecho de opción del acreedor
}

José Maximiliano Rivera Restrepo*

Universidad Gabriela Mistral (Chile)

jose.rivera@ugm.cl

Fecha de recibido: 20 de junio de 2016 / Fecha de aprobación: 30 de julio de 2016

\section{Resurmen}

La presente investigación tiene por finalidad analizar la diligencia como presupuesto del derecho de opción del acreedor, ante el incumplimiento contractual. Particularmente, se analizará este elemento, a partir de la legislación, doctrina y jurisprudencia españolas.

\section{Palabras Clave}

Derecho de opción / resolución / contratante diligente / derechos del acreedor / incumplimiento contractual / derecho de remedios

\section{Abstract}

This research aims to analyze the diligence and the right of option of the creditor budget before the breach of contract. In particular, this element will be analyzed from the legislation, doctrine and jurisprudence Spanish

Key words

Right option / resolution / contracting diligent / creditor's claim / breach of contract / law remedies

\footnotetext{
${ }^{*}$ El autor inició sus estudios en el Instituto Nacional y en la Facultad de Filosofía y Humanidades de la Universidad de Chile. Abogado de la Universidad de Chile y Magíster en Derecho, con mención en Derecho Privado por la Universidad de Chile. Máster Universitario en Derecho Privado por la Universidad Complutense de Madrid. Doctor en Derecho Civil por la Universidad Complutense de Madrid. Notario Público, Conservador de Bienes Raíces, de Comercio, Minas y Archivero Judicial Suplente de Tocopilla. Profesor de Jornada de Derecho Civil en la Universidad Gabriela Mistral. Diplomado en Docencia Universitaria (C), Universidad Gabriela Mistral. Dirección postal: Ricardo Lyon N ${ }^{\circ} 1177$, Providencia, Santiago de Chile, Código Postal: 7510549.
} 

Solución. Conclusión. Índice de sentencias. Bibliografía citada.

\section{Introducción}

El derecho de opción del acreedor presenta, en mi opinión, un fuerte sustrato ético o moral, toda vez que, lo que constituye una sanción para el contratante incumplidor, es, a la vez, un premio para la buena fe del contratante cumplidor. Los intereses y expectativas de éste, no pueden verse afectados por la actitud negligente o dolosa del otro contratante.

En este trabajo, se intenta examinar la diligencia del contratante cumplidor, como presupuesto básico para que opere el derecho de opción del acreedor, ante el incumplimiento contractual.

\section{La diligencia como elemento del derecho de opción del acreedorı}

Para que opere el derecho de opción del acreedor, ante el incumplimiento contractual, es necesario que el acreedor haya cumplido con su propia obligación o se encuentre llano a hacerlo. ${ }^{2}$ Esto no lo dice el artículo II 24 del CC español, ${ }^{3}$ pero se deriva de las disposiciones que rigen el incumplimiento. ${ }^{4}$ Aun cuando en el sistema

\footnotetext{
${ }^{1} \mathrm{Al}$ respecto, vid.: De Cossio y CorRal, A. (1987) Instituciones de Derecho civil, I (Revisado y puesto al día por Manuel de Cossío y Martínez. Madrid: Editorial Civitas, S. A.), p. 295; RuIz SERRAmAlerA, R. (1981): Derecho civil. Derecho de obligaciones I. Las obligaciones en general (Madrid: Universidad Complutense de Madrid, Facultad de Derecho, Secc. de Publicaciones), p. 104; VÁzQuez IruzubIeTA, C. (1989): Doctrina y jurisprudencia del Código civil (3. ${ }^{a}$ Edición. Prólogo de Luis Diez-Picazo. Madrid: Editorial Revista de Derecho Privado), p. 1714.

${ }^{2}$ En este punto, cfr.: Mosco, L. (1962): Código Civil, Libro IV, Título I, Capitulo III, artículo 1.124. La resolución de los contratos por incumplimiento (Notas sobre legislación española por José Salamero Cardo. Barcelona: Nereo), p. 11; OGAYAR Y AYLlón, T. (1983): Efectos que produce la obligación bilateral. Doctrina jurisprudencial sobre los artículos 1.124 y 1.504 del Código Civil (Pamplona: Editorial Aranzadi, S. A.), pp. 77 y ss.

${ }^{3}$ En este sentido, CLEMENTE MEORO señala que: "Aunque no cabe encontrar en el artículo 1124 de nuestro Código Civil indicio alguno que apunte al requisito del cumplimiento del acreedor, nuestro Tribunal Supremo ha establecido de manera reiterada que la acción resolutoria corresponde a quien cumplió lo que le incumbía y sufre el incumplimiento de la otra parte, por lo que no tiene derecho a pedir la resolución el contratante que incumple sus obligaciones [...]". Clemente MeORO, M. E. (1998): La resolución de los contratos por incumplimiento: presupuestos, efectos y resarcimiento del daño (Valencia: Tirant lo Blanch), p. 8.

${ }^{4}$ En este mismo sentido se pronuncia DE COSSIO y CORRAL, quien señala que: "[...] Es preciso también que el que reclama la resolución del contrato haya cumplido su compromiso, o al menos que no se haya constituido en situación de incumplimiento. Aunque en principio la determinación de a cuál de los dos partes deba imputarse el incumplimiento sea una cuestión de hecho puede, no obstante, llegar a constituir una cuestión de derecho, cuando la base para la determinación del incumplimiento está, más que en los actos ejecutados, en la transferencia jurídica que haya de atribuirse a los mismos". DE COSSIO y CORRAL (1987), p. 295. En este mismo sentido, MORENO GIL, comentando la STS de 21 de febrero de 1991, señala lo siguiente: "La resolución sólo puede ser solicitada por el que ha cumplido su parte. El hecho incumplido ha de ser de tal entidad que impida el fin normal del contrato". MORENO GIL, Ó. (2006): Código civil y jurisprudencia concordada (Madrid: Imprenta Nacional del Boletín Oficial del Estado), p. 1074. Por su parte, PUIG BRUTAU señala que: "El contratante que ejercite el derecho de resolución no ha de haber incurrido por su parte en incumplimiento". PUig Brutau, J. (1988): Fundamentos de Derecho civil, I (Vol. II. Cuarta Edición Revisada.
} 
jurídico español no se encuentra consagrada expresamente la exceptio non adimpleti contractus. Sin embargo, la doctrina ha señalado que se encuentra implícitamente reconocida en los artículos 11005 y II $24 \mathrm{CC}$ español y en la jurisprudencia, ${ }^{6}$ y encuentra fundamento en el principio de la buena fe. ${ }^{7}$ La doctrina y la jurisprudencia exigen como presupuesto de la acción resolutoria, que el perjudicado no haya dejado de cumplir su obligación, ni aun cuando su incumplimiento sea de poca monta, ${ }^{8}$ pues de lo contrario, debe aceptar las consecuencias de su conducta. ${ }^{9}$ Lo anterior corresponde a una cuestión de hecho ${ }^{10}$ determinada por los jueces de fondo y, por tanto, no susceptible de recurso de casación, "I aun cuando existe cierta jurisprudencia contraria. ${ }^{12}$ Este requisito ha sido ratificado por la jurisprudencia ${ }^{13}$ y se encuentra presente en numerosos sistemas jurídicos europeos. ${ }^{14}$ Se ha dicho

\footnotetext{
Derecho General de las Obligaciones. Barcelona: Bosch, Casa Editorial, S. A.), p. 27.
}

${ }^{5}$ El artículo 1100 del CC español, dispone que: "Incurren en mora los obligados a entregar o a hacer alguna cosa desde que el acreedor les exija judicial o extrajudicialmente el cumplimiento de su obligación. No será, sin embargo, necesaria la intimación del acreedor para que la mora exista: $1 .{ }^{\circ}$ Cuando la obligación o la ley lo declaren así expresamente. 2. ${ }^{\circ}$ Cuando de su naturaleza y circunstancias resulte que designación de la época en que había de entregarse la cosa o hacerse el servicio, fue motivo determinante para establecer la obligación. En las obligaciones recíprocas ninguno de los obligados incurre en mora si el otro no cumple o no se allana a cumplir debidamente lo que le incumbe. Desde que uno de los obligados cumple su obligación, empieza la mora para el otro".

${ }^{6}$ En este sentido, la STS de 19 de mayo de 1008, dispone que: "[...] Por otro lado, es necesario que quien ejercite la acción resolutoria no esté en la misma situación incumplidora, salvo que sea consecuencia del previo incumplimiento del otro contratante -sentencias de 21 de octubre de 1994 (RJ 1994, 8146) y 7 de junio de 1995 (RJ 1995, 4632) -". STS de 19 de mayo de 2008, (RJ/2008/366).

${ }^{7}$ Cfr.: Bercovitz RodríGuez-CANo, R. (Direct.) (2013): Comentarios al Código civil, VI (Valencia: Tirant lo Blanch), pp. 8226-8227.

${ }^{8}$ Vid.: STS de 26 de junio de 1995, (RJ/1995/ 5116), 8 de julio de 1993, (RJ/1993/ 6115), 14 de octubre de 1992, (RJ/1992/7557) y 28 de septiembre de 1992, (RJ/1992/7328). Cfr.: PASQUAu Liaño, M. (Direct.); AlBIEZ DOHRMANN, K. J. y LÓPEZ FRÍAS, A. (Coords.) (2009): Jurisprudencia civil comentada. Código Civil, II (Segunda Edición. Granada: Editorial Comares, S. L.), p. 1910.

${ }^{9}$ A nivel de Derecho comparado, el CóDIGo Civil DE LA RePÚBLICA DE CUBA, expresamente se refiere a este requisito, al disponer, en su artículo 306 lo siguiente: "En las obligaciones recíprocas, el que ha cumplido la que le corresponde puede exigir el cumplimiento o la ejecución a costa del otro obligado, o la resolución de la obligación, con indemnización de daños y perjuicios en todo caso". CóDIGO CIVIL DE LA REPÚBLICA DE CUBA (2005): (Ley n 59/1987 de 16 de julio. Anotado y concordado con los ordenamientos cubano y español. Ángel Acebo Penco y Leonardo B. Pérez Gallardo. Madrid: Dykinson, S. L.), p. 168.

${ }^{10}$ En este sentido, la STS de 5 de junio de 1995, decreta que: "[...] el problema de incumplimiento o cumplimiento del contrato es cuestión de hecho [...]". Cfr.: AlbÁCAR LóPez, J. L. y SANTOS BRIZ, J. (1995): Código civil. Doctrina y jurisprudencia (Actualización 1995. Madrid: Editorial Trivium S. A.), p. 617. En este mismo sentido, la STS de 7 de noviembre de 1973. Cfr.: AlbÁCAR LóPEZ, J. L. y SANTOS BRIZ, J. (1991): "Libro IV. De las obligaciones. Títulos I y II", en Código civil. Doctrina y jurisprudencia, IV (Doctrina, antecedentes y concordancias de Jaime Santos Briz y José Ángel Torres Lana, José Luis Albácar López. Direct., coord., selección de la jurisprudencia, índices y bibliografía). Madrid: Editorial Trivium S. A.), p. 180. Por su parte, la STS de 17 de marzo de 1999, decreta que: "[...] el tema relativo al cumplimiento o incumplimiento de un contrato es una cuestión de hecho y, en cuanto tal, sujeta a la libre apropiación de los juzgadores de la instancia [...]". Cfr.: FARRÉ AlEMÁN, J. Ma . (2000): Código civil comentado y concordado (Barcelona, Editorial Bosch, S. A.), p. 1069.

${ }^{11}$ Cfr.: SANTOS BRIZ, J. (1975): Derecho civil. Teoría y práctica, III (Madrid, Editorial Revista de Derecho Privado), p. 130.

${ }^{12}$ En este sentido, MORENO GIL señala que: "La declaración sobre el cumplimiento o incumplimiento de los contratantes, que, en principio es una cuestión fáctica, puede, sin embargo, constituir también una cuestión de derecho". [Comentario a la STS de 7-6-1991]. MORENO GIL (2006), p. 1073.

${ }^{13}$ Vid.: STS de 1 de junio de 1992 (RJ/1992/4891), 21 de octubre de 1959, (RJ/1959/3681) y 20 de diciembre de 1993, (RJ/1993/10086). Cfr.: PASQuAU LiAÑo; Albiez DohrmanN y LÓPEZ FRÍAS (2009), p. 1908. Se añaden, en este sentido, las STS de 21 octubre 1959; STS de 22 de marzo de 1950; STS de 20 de diciembre de 1975, STS de 26 de octubre de 1978, STS de 11 de mayo de 1979 y STS de 10 de noviembre de 1981. Cfr.: OGAYAR Y AYLLÓN (1983), pp. 78-79.

${ }^{14}$ Cfr.: Dell'AQuila, E. (1981): La resolución del contrato bilateral por incumplimiento (Prólogo de José Luis de los Mozos. Salamanca: Ediciones Universidad de Salamanca), p. 172. 
que la jurisprudencia española ha sido extremadamente cautelosa y que atiende a criterios subjetivos. La jurisprudencia italiana atendía al dato subjetivo de si existe utilidad o no para el acreedor, en la ejecución de la prestación tardía; la española atiende al grado de culpabilidad que tiene el contratante negligente en el incumplimiento. ${ }^{15} \mathrm{Si}$ el acreedor demanda de resolución, el deudor le opondrá a su requerimiento la excepción derivada del artículo I 100 (excepción de contrato no cumplido o non adimpleti contractus), 16 con lo cual la demanda de resolución no prosperará. ${ }^{17}$ La doctrina, tomando en cuenta varias sentencias del TS, ha dicho que: "Constituye un principio básico en materia de resolución contractual, aquel que niega dicha facultad al titular de una obligación recíproca, que hubiera dejado de cumplir lo que a él incumbía; es decir, para ejercitar la facultad resolutoria, el reclamante tiene que aparecer como fiel cumplidor, independientemente de la conducta atribuible a la parte contraria, [...] (STS I3-3-1990; RJ 1990, I693). En igual sentido, la STS 22-5-I99I (RJ I99I, 3783)". 18 Por su parte, la STS 22 de febrero de $20 \mathrm{II},(\mathrm{R} / / 20 \mathrm{I} / / 80)$ dispone que uno de los requisitos de procedencia de la acción resolutoria es: "[...] que quien ejercita esta acción no haya incumplido las obligaciones que le concernían, salvo si ello ocurriera como consecuencia del incumplimiento anterior del otro, pues la conducta de éste es la que motiva el derecho de resolución de su adversario y lo libera de su compromiso (entre otras SSTS 21 marzo de 1986 y 21 marzo 1994 La Ley-16.156-R )”.

DE BUSTOS GÓMEZ-RICO plantea que para que sea posible deducir la exceptio non adimpleti contractus, ${ }^{19}$ debe existir un incumplimiento de cierta entidad o cuantía, que suponga la frustración del fin del contrato, en términos razonables, es decir, que prive de los efectos económicos que le hubiera significado el cumplimiento oportuno de la obligación, para el contratante a quien se exige la resolución o el cumplimiento del contrato. ${ }^{20}$ Así lo ha reconocido la jurisprudencia, pues, si ambos contratantes han incumplido sus respectivas obligaciones, entonces no cabe la resolución. ${ }^{21}$

Con todo, según la doctrina, este presupuesto de la resolución viene matizado por ciertas sentencias que decretan que, para pedir la resolución de la obligación, el actor, puede haber incumplido igualmente su deber, pero éste se debe al incumplimiento precedente del demandado. ${ }^{22}$ Es decir, la conducta negligente del demandado, libera al

${ }^{15}$ Cfr.: CANo MARTínez de Velasco, J. I. (2009): La equidad en el Derecho privado (Barcelona: Bosch Editor), p. 48.

${ }^{16}$ También llamada "excepción de inejecución". Cfr.: la STS de 11 de marzo de 2011, que dispone: "[...] Y en segundo término, porque la decisión de la suministradora demandante de suspender la ejecución de su prestación estaba justificada por la excepción de incumplimiento del contrato (de suministro), a la que nos referimos, entre otras, en la sentencia 168/2.010, de 30 de marzo [...]". STS de 11 de marzo de 2011, (RJ/2011/132).

${ }^{17}$ Cfr.: LACRuz Berdejo, J. L.; SANChO Rebullida, F. de A.; LunA SERRANO, A.; Delgado EcheVerRía, J.; Rivero Hernández, F. y RAms Albesa, J. (2011): Elementos de Derecho Civil II. Derecho de Obligaciones (Vol. Primero, Parte General. Teoría General del Contrato. Quinta Edición, revisada y puesta al día por Francisco Rivero Hernández. Madrid: Dykinson), p. 194.

${ }^{18}$ Fernándio Xiol Ríos, F. J. (Direct.) (2010): Código Civil. Concordancias, notas y jurisprudencia (Madrid: Grupo El Derecho y Quantor, S. L.), p. 1235. Vid. también: STS de 8 de febrero de 1980, (RJ/1980/933); STS de 19 de abril de 1982, (RJ/1982/1957); STS de 21 de marzo de 1986, (RJ/1986/1275); STS de 25 de octubre de 1988, (RJ/1988/7637). Cfr.: FERNÁNDIO XIOL RÍOS (2010), p. 1235.

${ }^{19}$ Esta institución, al igual que el derecho de opción del acreedor, según la doctrina, se justifica por el carácter sinalagmático o recíproco del contrato. Cfr.: DE Bustos GómeZ-Rico, M.; Corbal Fernández, J. E.; DE LA EsPeranza, P.; GonzÁlez Olleros, J.; GonzÁlez Poveda, P.; MARÍn CAStÁN, F. y PAZ Rubio, J. Ma . (2009): Código Civil. Comentarios y Jurisprudencia (17 $7^{\mathrm{a}}$ Edición. Madrid: Colex), p. 811.

${ }^{20}$ Cfr.: De Bustos Gómez-Rico; Corbal Fernández; De la Esperanza; GonzÁlez Olleros; González POVEDA; MARÍN CASTÁN y PAZ RUBio, (2009), p. 811.

${ }^{21}$ Cfr.: MOSCO (1962), p. 15.

${ }^{22}$ En este sentido, DíEZ-PICAZO Y PONCE DE LEÓN señala que: "La facultad resolutoria corresponde al contratante que padece o sufre el incumplimiento y se ejercita frente al incumplidor. La jurisprudencia señala que no queda impedido el ejercicio de la acción resolutoria cuando el demandante ha incumplido también la obligación que le concernía, pero lo ha hecho como consecuencia de un incumplimiento anterior del demandado, planteando, con ello, el problema de los incumplimientos dobles [...]". DíEZ-PICAZO Y PONCE DE LEÓN, L. (2008): Fundamentos del Derecho civil patrimonial 
otro contratante de cumplir su compromiso. ${ }^{23}$ Sobre este punto, CLEMENTE MEORO señala lo siguiente: "Si atendemos a esta última doctrina, podemos llegar a la conclusión de que la correcta formulación de nuestra jurisprudencia no es la que establece como principio general el cumplimiento del acreedor demandante de la resolución, sino su no incumplimiento. En efecto, si «la conducta del que incumple primero es la que motiva el derecho de resolución y libera a la otra parte desde entonces de sus compromisos», el contratante que no ha cumplido -pero tampoco ha incumplido, porque aún no le correspondía cumplir- estará facultado para resolver la relación obligatoria. A la misma solución puede llegarse utilizando una argumentación a fortiori. Si quien ha incumplido a consecuencia del incumplimiento anterior del otro puede solicitar la resolución, con mayor motivo podrá hacerlo quien no ha incumplido, aunque tampoco ha cumplido". ${ }^{24}$ Agrega la doctrina, sobre la base lo que ha dicho la jurisprudencia, que este requisito se ha matizado, por cuanto se ha admitido la acción resolutoria, por el contratante que, no habiendo cumplido aún su obligación, su incumplimiento obedece o es consecuencia del incumplimiento del otro contratante. En este punto, el juez tiene facultades discrecionales para determinar si se cumple este requisito. También, el hecho de que el incumplimiento del actor se haya motivado por el incumplimiento de la contraparte, se trata de una cuestión de hecho, que deberá ser establecida por el tribunal en la sentencia definitiva. ${ }^{25}$ Aun cuando existe jurisprudencia contraria. ${ }^{26} \mathrm{El}$ criterio anterior ha sido recogido por la jurisprudencia, en la STS de 27 de octubre de 2004, que dispone: "[...] 5. Para emitir un juicio de valor positivo sobre procedencia de la resolución del vínculo contractual sinalagmático (sea a demanda del contratante no incumplidor dirigida a que la ineficacia sobrevenida del vínculo se declare, sea a demanda del supuesto incumplidor, interesado en obtener la declaración de que la voluntad resolutoria de la otra parte se actuó incorrectamente) es necesario que concurran los requisitos que recuerda la sentencia de 21 de marzo de 1994 (RJ I994, 2560), entre ellos que una de las partes de la relación haya incumplido de forma grave las prestaciones a su cargo. Debe tenerse en cuenta, por otro lado y como destacó la sentencia de 3 de junio de 1993 (RJ 1993, 5259), que si no está legitimado para pretender la resolución del vínculo contractual el contratante que incumple sus obligaciones, sí lo está el que lo hace a consecuencia del incumplimiento anterior del otro, pues la conducta del que incumple primero es la que motiva el derecho a la resolución". 27

\section{Solución}

La jurisprudencia ha negado sistemáticamente la facultad para emprender cualquiera acción por parte del contratante incumplidor. Se puede citar la STS de 18 de octubre de 20I I, que hace alusión a la STS de 8 de octubre de 2008, que veda la posibilidad para solicitar la resolución contractual a la parte que no ha cumplido su obligación.

(Vol. II. Las relaciones obligatorias. Sexta Edición. Navarra: Editorial Aranzadi, S. A.), p. 819.

${ }^{23}$ Cfr.: Clemente MeORo (1998), p. 38.

${ }^{24}$ Clemente MeORo (1998), p. 39.

${ }^{25}$ Cfr.: Montés PenadÉs, V. L. (1989): Comentarios al Código Civil, XV, Vol. 1, artículos 1.088 a 1.124 del Código Civil, disponible en www.vlex.com (Fecha de la consulta 4 de marzo de 2014), p. 31.

${ }^{26}$ En este sentido, la STS de 8 de febrero de 1980 decreta lo siguiente: "Como estableció la sentencia de esta Sala de 30 de abril de 1969, siguiendo la pauta marcada por las de 9 de junio de 1950 y 28 de febrero de 1958, si bien la declaración sobre incumplimiento del contrato por parte de uno de los contratantes, puede ser una questio facti, cuando ello depende sólo de que se hayan realizado u omitido determinados actos, declaración que en este supuesto sólo es atacable por el cauce del número $7 .^{\circ}$ del artículo 1.692 de la LEC, puede también constituir una questio iuris, cuando la base para la determinación del incumplimiento esté, más que en los actos ejecutados, en la trascendencia jurídica de dichos actos, ya que partiendo de los supuestos de hecho admitidos en la instancia, su valoración jurídica, sin necesidad de modificarlos, es atacable al amparo del número $1 .^{\circ}$ del referido artículo 1.692 de la Ley Procesal Civil, y ello máxime cuando en el caso concreto por la citada sentencia de 30 de abril de 1969, con fundamento en situación fáctica, en puntos generales coincidente en ambas instancias, se ha decidido el caso con distinto signo en cada una de ellas". Cfr.: ALBÁCAR LÓPEZ y SANTOS BRIZ (1995), p. 183.

${ }^{27}$ STS de 27 de octubre de 2004, (RJ/2004/7196). 
En esta misma línea se encuentran las STS de 7 de octubre de 2005, STS de 9 de diciembre de 2004, STS de 22 de abril de 2004, STS de 29 de julio de 1999, entre otras. ${ }^{28}$

Estimo que el contratante se considera diligente, en cualquiera de los siguientes casos: (a) Cuando efectivamente cumplió con su obligación; (b) cuando no ha cumplido porque tiene un plazo suspensivo pendiente; (c) cuando no ha cumplido, pero tiene a su favor una condición suspensiva pendiente; y (d) cuando no ha cumplido, pero está llano o dispuesto a hacerlo. ${ }^{29}$ Hay que agregar que también se considera contratante diligente el cesionario del crédito, pues ocupa la misma posición jurídica que tenía el cedente en la relación jurídica incumplida. ${ }^{30}$ Así lo ha decretado la jurisprudencia, v. gr., en la STS de 4 de julio de $201 \mathrm{I}$, se dispone que: "Ahora bien, como se dijo con anterioridad, estamos en presencia de un contrato bilateral que genera para las partes obligaciones recíprocas, siendo por ello que la jurisprudencia viene también exigiendo para acceder a la petición resolutoria, que el vendedor haya cumplido sus obligaciones contractuales. A tal efecto la jurisprudencia del TS ha sostenido reiteradamente en sentencia por ejemplo de 13 de diciembre de 2000, recogiendo lo dicho en sentencia de 12 de marzo de 1985 que «como tiene reiteradamente declarado esta Sala, en exégesis del art. I504, con su complemento del II 24 del Código Civil, en las obligaciones bilaterales o recíprocas como son las que por su naturaleza provienen del contrato cuestionado, la facultad de resolución parte de la base de que quien la ejercita haya cumplido con carácter previo, fielmente frente a la contraparte que haya dejado de hacerlo [...]»". ${ }^{31}$

Por último, frente a la petición de resolución recíproca, (mediante acción y reconvención) sin existir incumplimiento grave o esencial de ambas partes, el tribunal no puede estimar la resolución, ni judicial ni extrajudicial. Con todo, el juez debe dictar una sentencia (por el principio dispositivo que rige al proceso civil), sin que imponga una indemnización de daños y perjuicios. En esta línea se pueden mencionar la STS de 20 de julio de $200 \mathrm{I}$ y STS de 4 de octubre de $201 \mathrm{I} .32$

${ }^{28}$ Cfr.: RodRíGUEZ-RosADO, B. (2013): Resolución y sinalagma contractual (Málaga: Marcial Pons, Ediciones Jurídica y Sociales, S. A.), p. 170. Sobre este mismo punto, y desde el punto de vista doctrinario, DELL'AQUILA señala lo siguiente: "No es difícil contestar a esta pregunta: porque se halla en armonía con los principios generales de equidad que quien comete un acto ilícito no puede aprovecharse de las consecuencias jurídicas, para él convenientes, que deriven de este mismo hecho. Es ésta una regla equitativa que se encuentra en sendas máximas del derecho romano: «nemo ex suo delicto meliorem suam condicionem facere potest»; «nemo de improbitate sua consequitur actionem», etc.". DELL'AQUILA (1981), p. 172.

${ }^{29}$ En este mismo sentido, OGAYAR Y AYLLÓN, señala como uno de los requisitos de procedencia de la acción resolutoria, a la "exigibilidad de las obligaciones". Cfr.: OGAYAR Y AYLLÓN (1983), pp. 74 y ss.

${ }^{30}$ Cfr.: DíEZ-PICAZO Y PONCE DE LEÓN (2008), p. 819.

${ }^{31}$ STS de 4 de julio de 2011, (RJ/2011/5964). En este mismo sentido, la jurisprudencia ha declarado que: "Es doctrina jurisprudencial, reiteradamente proclamada por esta Sala, que la facultad de resolver las obligaciones que otorga el art. 1.124 del Código Civil se establece sólo a favor del perjudicado, y no del que deja de cumplir aquellas que le incumben; y como la apreciación de tal extremo, de puro hecho, es de la facultad privada de la Sala sentenciadora, a menos que se desvirtúe demostrando, con actos o documentos auténticos, la evidente equivocación del juzgador, en la forma autorizada por el número séptimo del art. 1.692 de la Ley Procesal, es claro que, cuando, como ahora acontece, se articula el recurso al amparo sólo del número primero del citado precepto, hay que partir, para su resolución, del respeto absoluto a los hechos declarados probados. Al aplicar tal doctrina al presente recurso, ante las terminantes declaraciones de la Sala afirmando en síntesis, que fue el actor quien se negó, con pretextos injustificados, a consumar la transacción, no obstante que el recurrido hizo por su parte cuanto le fue posible para llevarla a feliz término, carecen de eficacia las infracciones de los arts. 1.466 y 1.500 del Código Civil, en relación con el 1.124, invocadas en los dos primeros motivos, por basarse claramente, en aseveraciones contrarias a los del Tribunal «a quo», haciendo supuesto de la cuestión, lo que no es lícito en casación. (T. S. Sentencia 12 marzo 1947)". Cfr.: MosCo (1962), p. 21.

${ }^{32}$ Cfr.: RODRÍGUEZ-ROSADO (2013), p. 175. 
En este punto, conviene mencionar que el ejercicio judicial de la facultad resolutoria, se puede verificar por medio de una demanda o reconvención, formulada por el contratante cumplidor, mas no se puede deducir como excepción procesal..$^{33}$ En este sentido, se ha pronunciado la jurisprudencia. ${ }^{34}$

\section{Conclusión}

La diligencia constituye quizás, el fundamento más próximo del derecho de opción del acreedor, él supone la contrapartida de la negligencia o malicia con que actúa el contratante incumplidor. El derecho de opción del acreedor, se funda remotamente en el principio de la equidad natural, principio que fundamenta este requisito.

\section{Índice de Sentencias}

STS de II de marzo de 20II, (RJ/20I I/I32).

STS de 19 de mayo de 2008, (RJ/2008/366).

STS de 27 de octubre de 2004, (RJ/2004/7/96).

STS de 26 de junio de 1995, (RJ/I995/ 5I I6).

STS de 20 de diciembre de 1993, (RJ//993//0086).

STS de 8 de julio de 1993, (RJ/I993/ 6II5).

STS de I4 de octubre de 1992, (RJ/I992/7557).

STS de 28 de septiembre de 1992, (RJ/I992/7328).

STS de I de junio de 1992 (RJ/I992/489I).

STS de 22 de mayo de 1991 (RJ/I99I/3783).

STS de 13 de marzo de 1990, (RJ/I990/1693).

STS de 25 de octubre de 1988, (RJ/I988/7637).

STS de 21 de marzo de 1986, (RJ/I986/I275).

STS de 19 de abril de 1982, (RJ//982//957).

STS de 8 de febrero de 1980, (RJ/I980/933).

STS de 2 I de octubre de 1959, (RJ/I959/368I).

\section{Bibliografía Citada}

AlbÁCAR LÓPEZ, J. L. y SANTOS BRIZ, J. (1995): Código civil. Doctrina y jurisprudencia (Actualización 1995. Madrid: Editorial Trivium S. A.).

( 199 I): “Libro IV. De las obligaciones. Títulos I y II”, en Código civil. Doctrina y jurisprudencia, IV (Doctrina, antecedentes y concordancias de Jaime Santos Briz y José Ángel Torres Lana, José Luis Albácar López. Direct., coord., selección de la jurisprudencia, índices y bibliografía). Madrid: Editorial Trivium S. A.), Pp. 3-843.

Bercovitz Rodríguez-Cano, R. (Direct.) (20I3): Comentarios al Código civil, VI (Valencia: Tirant lo Blanch).

CANO MARTíneZ DE VelASCO, J. I. (2009): La equidad en el Derecho privado (Barcelona: Bosch Editor).

\footnotetext{
${ }^{33}$ Cfr.: Puig i Ferriol; Gete-Alonso y CALERA; Gil RodríGuez y Hualde SÁnCHez, Manual de Derecho civil, Op. Cit., p. 137.

${ }^{34}$ STS de 18 de marzo de 1991, 19 de noviembre de 1994, 24 de octubre de 1995, 17 de febrero de 1996, 20 de junio de 1996, 20 de junio de 1998, 20 de septiembre de 1999, 6 de octubre de 2000, 18 de diciembre de 2006 y 17 de julio de 2009. Cfr.: MARTORELl ZuluetA, P. (Coord.). (2011): Código Civil, Jurisprudencia sistematizada (Valencia: Editorial Tirant lo Blanch), p. 1276.
} 
CLEMENTE MEORO, M. E. (1998): La resolución de los contratos por incumplimiento: presupuestos, efectos y resarcimiento del daño (Valencia: Tirant lo Blanch).

Código CIVIL DE LA RePÚBLICA DE CUBA (2005): (Ley n 59/I987 de 16 de julio. Anotado y concordado con los ordenamientos cubano y español. Ángel Acebo Penco y Leonardo B. Pérez Gallardo. Madrid: Dykinson, S. L.).

De Bustos Gómez-Rico, M.; Corbal Fernández, J. E.; De la EsPeranzA, P.; GonzÁlez Olleros, J.; GonZÁlez Poveda, P.; MARÍN CASTÁN, F. y PAZ RuBIO, J. Ma . (2009): Código Civil. Comentarios y Jurisprudencia (I7 Edición. Madrid: Colex).

De Cossio y CoRRAL, A. (1987): Instituciones de Derecho civil, I (Revisado y puesto al día por Manuel de Cossío y Martínez. Madrid: Editorial Civitas, S. A.).

Dell'AQUILA, E. (198I): La resolución del contrato bilateral por incumplimiento (Prólogo de José Luis de los Mozos. Salamanca: Ediciones Universidad de Salamanca).

DíEZ-PICAZO Y PONCE DE LEÓN, L. (2008): Fundamentos del Derecho civil patrimonial (Vol. II. Las relaciones obligatorias. Sexta Edición. Navarra: Editorial Aranzadi, S. A.).

FARré AlemÁN, J. Ma . (2000): Código civil comentado y concordado (Barcelona, Editorial Bosch, S. A.).

FERNÁNDIO XIOL Ríos, F. J. (Direct.) (20I0): Código Civil. Concordancias, notas y jurisprudencia (Madrid: Grupo El Derecho y Quantor, S. L.).

lacruz Berdejo, J. L.; Sancho Rebullida, F. de A.; luna Serrano, A.; Delgado EcheVerría, J.; Rivero HERNÁNDEZ, F. y RAMS AlBESA, J. (20l I): Elementos de Derecho Civil II. Derecho de Obligaciones (Vol. Primero, Parte General. Teoría General del Contrato. Quinta Edición, revisada y puesta al día por Francisco Rivero Hernández. Madrid: Dykinson).

KING JR., M. L. (1963) Discurso “I have a dream ...”. Disponible en www.archives.gov (Fecha de la Consulta el 22 de junio de 2016).

Martorell Zulueta, P. (Coord.). (20I I): Código Civil, Jurisprudencia sistematizada (Valencia: Editorial Tirant lo Blanch).

Montés Penadés, V. L. (1989): Comentarios al Código Civil, XV, Vol. I, artículos I.088 a I.I24 del Código Civil, disponible en www.vlex.com (Fecha de la consulta 4 de marzo de 20I4), pp. I-93.

MORENO GIL, Ó. (2006): Código civil y jurisprudencia concordada (Madrid: Imprenta Nacional del Boletín Oficial del Estado).

Mosco, L. (1962): Código Civil, Libro IV, Título I, Capítulo III, artículo I.I24. La resolución de los contratos por incumplimiento (Notas sobre legislación española por José Salamero Cardo. Barcelona: Nereo).

OGAYAR Y AYLLÓN, T. (1983): Efectos que produce la obligación bilateral. Doctrina jurisprudencial sobre los artículos I. 124 y 1.504 del Código Civil (Pamplona: Editorial Aranzadi, S. A.).

Pasquau liaño, M. (Direct.); Albiez DohrmanN, K. J. y LóPez FríAS, A. (Coords.) (2009): Jurisprudencia civil comentada. Código Civil, II (Segunda Edición. Granada: Editorial Comares, S. L.).

PUIG BRUTAU, J. ( I988): Fundamentos de Derecho civil, I (Vol. II. Cuarta Edición Revisada. Derecho General de las Obligaciones. Barcelona: Bosch, Casa Editorial, S. A.).

RODRÍGUEZ-ROSADO, B. (20I3): Resolución y sinalagma contractual (Málaga: Marcial Pons, Ediciones Jurídica y Sociales, S. A.).

RUIZ SERRAMALERA, R. (198I): Derecho civil. Derecho de obligaciones I. Las obligaciones en general (Madrid: Universidad Complutense de Madrid, Facultad de Derecho, Secc. de Publicaciones).

SANTOS BRIZ, J. (1975): Derecho civil. Teoría y práctica, III (Madrid, Editorial Revista de Derecho Privado).

VÁZQUEZ IRUZUBIETA, C. (1989): Doctrina y jurisprudencia del Código civil (3. ${ }^{a}$ Edición. Prólogo de Luis Diez-Picazo. Madrid: Editorial Revista de Derecho Privado). 